\title{
MRS Establishes New Workshop Series
}

The Materials Research Society has established the MRS Workshop Series, a new service for the materials community. MRS Workshops will deal with highly focused and compelling subjects, just as the MRS Fall or Spring symposia do. However, the workshops will be aimed at targeted audiences, offer a high level of discussion, be limited in size (less than about 125 participants), and will not compete with any other MRS activities. They will be scheduled at times and places other than the Fall and Spring meetings to offer attendees a more in-depth review of important topics than is typically allowed in a "snapshot" symposium.

The first two workshops in the MRS series are scheduled for June 1999 in San Jose, CA on the topics of "Simulations of Thin Films Processing"-organized by George Gilmer, Lucent Technologies; Imran Hashim, Applied Materials; and Paco Leon, Intel-and "Tribology on the 300th Anniversary of Amontons' Law"organized by Michael Drory, Timken Aerospace-MPB and Mark O. Robbins, Johns Hopkins University.

"The need to provide a different type of forum to address very special educational needs has been evident to us for some time," said MRS Past President Robert Nemanich. "We are pleased to be able to offer two timely topics in 1999 to kick off this new program." The workshop format will consist primarily of in-depth presentations by acknowledged experts while also allowing for selected solicited talks and posters. Workshop attendees will be able to focus their full attention to the topic over a 2-3-day period.

To learn more about the 1999 workshops and future workshop schedules, or to suggest a topic for a future workshop, contact MRS Member Services at 724-7793003 or at info@mrs.org.

\section{UPCOMING CONFERENCE}

\section{COLA ' 99 to be Held in Germany in July}

The 5th International Conference on Laser Ablation (COLA '99) will be held in Göttingen, Germany on July 19-23, 1999. The co-chairs are J.S. Horwitz of the Navy Research Laboratory (USA), H-U. Krebs of the Institut für Materialphysik (Germany), K. Murakami of the University of Tsukuba (Japan), and M. Stuke of the Max-PlankInstitute (Germany).

The symposium topics are

- Mechanisms, Modelling \& Simulation

- Dynamics, Fast \& Ultrafast

- Desorption, Phase Explosion

- Plume/Plasma

- Absorption of Energy

- Role of Kinetic Energy

- Light Emission/X-Ray

- Clusters \& Nanoparticles
- Pulsed Laser Deposition (PLD)

- Deposition of Thin Film (Hetero-)

Structures

- New Materials (Ferroelectric, Ferromagnetic, Superlattices, Superconductive, Magnetoresistance)

- Target Materials

- Microfabrication of Polymers, Metals, and Ceramics

- Laser Cleaning

- Surface Modification

- In situ Diagnostics

- Analytic Spectroscopy and Forensic Analysis

- Industrial Applications

- Synthesis of Nanomaterials

- Scale-Up of PLD for Large Areas

- Medical Applications
- Self Organization

- Biotechnology

- MALDI

- Surface/Materials Analysis and Characterization

- Instrumentation

- New Laser Sources and Comparison to

Other Energetic Beams

- VUV Laser Ablation

- Micro- and Nanolithography

- Combinatorial PLD

- Perspectives \& Challenges

The conference will include an equipment exhibit on July 20-22 and published proceedings. The one-page abstract deadline is March 31, 1999. For further information, fax to 49-551-201-1330 or visit website http:// www.mpibpc.gwdg.de/COLA_99/.

\section{MRS BULLETIN SEEKS IUMRS NEWS ON}

Upcoming Meetings

- Conference Reports

- Important Technical Developments

\section{Research News \\ Policy Issues \\ - Educational Initiatives}

\author{
MRS Bulletin, Materials Research Society \\ 506 Keystone Drive, Warrendale, PA 15086-7573 USA \\ E-mail: bulletin@mrs.org or gabrielle.long@nist.gov
}

Fax: 724-779-8313 